\title{
Higher Mortality from Covid19 in Patients with Renal Dysfunction in A Multicultural Multi-Ethnic Population
}

\section{Satish Chandrasekhar Nair ( $\sim$ satchi2000@outlook.com )}

Tawam Hospital, Department of Academic Affairs \& College of Medicine, UAE University, Al Ain Huda Imam Gasmelseed

Al Ain Hospital, Department of Infectious Disease, Internal Medicine, Al Ain

\section{Asad Afroz Khan}

Tawam Hospital, Department of Infectious Disease, Internal Medicine, Al Ain

Ibrahim Nageh Khafagy

Al Ain Hospital Department of Pharmacy, Al Ain

Hashim Ibrahim Abdrhman

Al Ain Hospital, Department of Infectious Disease, Internal Medicine, Al Ain

Aqeel Aziz Saleem

Tawam Hospital, Department of Infectious Disease, Internal Medicine, Al Ain

Jayadevan Sreedharan

Gulf Medical University, Department of Epidemiology, Ajman

Ahmed Husain Alhosani

Tawam Hospital, Department of Academic Affairs, Internal Medicine, Al Ain

Amatur Rahman Siddiqua

Tawam Hospital, Department of Academic Affairs, Internal Medicine, Al Ain

Amna Riaz Ahmed

Tawam Hospital, Department of Academic Affairs, Internal Medicine, Al Ain

Aya Imad Shubbar

Tawam Hospital, Department of Academic Affairs, Internal Medicine, Al Ain

\section{Majd Munir Farajallah}

Tawam Hospital, Department of Academic Affairs, Internal Medicine, Al Ain

\section{Abdul Rahman Aleissaee}

Tawam Hospital, Department of Academic Affairs, Internal Medicine, Al Ain

Alan Mohammad Hamadeh

Tawam Hospital, Department of Academic Affairs, Internal Medicine, Al Ain

\section{Khlood Mustafa Bashir}

Tawam Hospital, Department of Academic Affairs, Internal Medicine, Al Ain

\section{Haneen Bassam Choker}


Tawam Hospital, Department of Academic Affairs, Internal Medicine, Al Ain

\section{Mohamed Nasir Alzaabi}

Tawam Hospital, Department of Academic Affairs, Internal Medicine, Al Ain

\section{Saif Saeed Alshehhi}

Tawam Hospital, Department of Academic Affairs, Internal Medicine, Al Ain

\section{Maitha Ali Alblooshi}

Tawam Hospital, Department of Academic Affairs, Internal Medicine, Al Ain

\section{Fatmah Ali Safdani}

Tawam Hospital, Department of Academic Affairs, Internal Medicine, Al Ain

\section{Rajish Sanjit Shil}

Tawam Hospital, Department of Academic Affairs, Internal Medicine, Al Ain

\section{Fuad Wardan Habbal}

Tawam Hospital, Department of Academic Affairs, Internal Medicine, Al Ain Abdulrahman Wael Alanqar

Tawam Hospital, Department of Academic Affairs, Internal Medicine, Al Ain

\section{Wafa Fayez Douleh}

Al Ain Hospital, Department of Infectious Disease, Internal Medicine, Al Ain

\section{Research Article}

Keywords: Gulf, United Arab Emirates, Infectious Disease, Kidney Disease, Mortality

Posted Date: February 26th, 2021

DOI: https://doi.org/10.21203/rs.3.rs-243317/v1

License: (c) (1) This work is licensed under a Creative Commons Attribution 4.0 International License.

Read Full License 


\section{Abstract \\ Background}

Despite previous exposure to coronavirus epidemics a few years ago, limited clinical and epidemiological information is available from the United Arab Emirates (UAE). The UAE is the second most affected country amongst the Gulf Cooperation Council Countries by Covid19. Distinctly, the UAE has a population of almost 9.2 million, with fewer than $12 \%$ UAE nationals, and the rest immigrants, mainly unskilled labourers. The disparate socio-economic structure, crowded housing conditions, multi-ethnic, multicultural population offers a unique set of challenges in Covid19 disease management.

\section{Methods}

In order to assess patient characteristics and survival for patients infected with Covid19, electronic patient data was retrospectively abstracted from the medical records of two designated public Covid19 referral hospitals, and subjected to statistical analysis.

\section{Results}

From, the total of 3072 patients, less than one-fifth were females, the Asian population (71.2\%), followed by Middle Eastern Arabs (23.3\%) were the most infected by the virus. Mortality was low among the Asian population. Diabetes Mellitus $(26.8 \%, p<0.001)$, hypertension $(25.7 \%, p<0.001)$, and heart disease $(9.6 \%$, $p<0.01$ ) were the most prevalent comorbidities observed and decreased survival by $2-3$ fold. Kidney disease escalated mortality rate by almost eight-fold high $(19.4 \%, p<0.001)$, as compared to patients without kidney disease. Higher age of patients between 51 and 65 years, significantly decreased the odds for survival (Crude OR 14.1, $p<, 0.001$ ) and (Adjusted OR 12.3, $p<0.001$ ), and patient age beyond 66 years, further significantly decreased the odds for survival (Crude OR 36.1, $p<0.001$ ) and (Adjusted OR 26.6,p< 0.001). Kidney disease as comorbidity significantly diminished the survival rates (Crude OR 9.6,p $<0.001$ ) and (Adjusted OR 5.7, p < 0.001), as compared to those without kidney dysfunction.

\section{Conclusion}

Although Asian population was the highest infected by Covd19, their mortality rate was low (2.6\%), compared to other nationalities. Older ages above 51 years decreased the odds of survival significantly. Despite other comorbidity risks, kidney dysfunction contributed to enhanced mortality by over eight-fold and reduced the odds of survival (Adjusted OR 26.6), compared to those patients without kidney dysfunction. Our findings are important in the management of the Covid19 disease in the region with similar economic, social, cultural and ethnic background. 


\section{Background}

The Covid19 viral infection outbreak following the first report from Wuhan, China, in December 2019, has headlined for global attention [1]. The rapid infectivity of the severe acute respiratory syndrome (SARSCoV-2), a novel and highly communicable pathogen, prompted the World Health Organization (WHO) to escalate the outbreak to a pandemic on March 11, 2020 [2]. The SARS-CoV-2 or Covid19 causing severe acute respiratory failure, needing hospitalization for less than thirty percent of those severely ill eroded healthcare resources and medical supplies, culminating in a global public health crisis that mankind had not witnessed before [3]. Since the first report of the outbreak, SARS-CoV-2 (Covid19) has infected almost 109 million people, and caused almost 2.4 million fatalities in 218 countries of the world, until February $14,2021[4]$.

The UAE United Arab Emirates (UAE) occupies a strategic location between Europe, Asia, and Africa, and is geographically closer to China. The UAE is a member country of the Gulf Cooperation Council, a political and economic union of five other Arab states, including Bahrain, Kuwait, Oman, Qatar, and Saudi Arabia [5]. In recent years, the UAE has transformed from a traditional to a state-of-the-art modern country, diversifying away from financial reliance on oil, to develop into a knowledge-based economy [6-7]. The strategic location and a growing economy have catapulted the UAE to become the epicenter for travel, transit, trade, and business [7]. Distinctively, the citizens of the UAE contribute to less than twelve percent of the total nine million population. The vast majority are immigrants from almost eighty other countries [6]. Southeast Asians, especially unskilled laborers and the Middle Eastern Arabs constitute the bulk of the immigrant population. The Covid19 outbreak was first reported in the United Arab Emirates on February 29, 2020, when the first five cases were identified. Almost ten weeks later the number of positive Covid19 cases surged to 1695 . Despite, 346,000 positive Covid1 9 cases, the number of deaths in the UAE remained low at less than $0.3 \%$ until February $14,2021[4,8]$. Social disparity is a significant contributor for the spread of infectious diseases. The disparate socioeconomic structure among the immigrants, and the multiethnic multicultural patient population in the UAE, offers unique set of challenges in Covid19 disease management [9]. Therefore, the objectives of this study were to assess the mortality rate for Covid19 infected patients in a multicultural multiethnic population of the United Arab Emirates, and to describe their characteristics and risk factors.

\section{Methods}

\section{Setting}

The study was conducted at the two government hospitals, Tawam and Al Ain hospital, both designated regional primary referral centers for Covid19 patient care, Joint Commission accredited, in Al Ain, the eastern region of the United Arab Emirates. The Covid19 Preparedness at Tawam and Al Ain hospitals (COPTA), a research group consisting of twenty-four physician-researchers, blinded to the study hypothesis conducted the retrospective review of patient electronic medical records (Cerner, USA). 


\section{Ethics Statement:}

The methods of the study were carried out in accordance with the International Conference for Harmonization ( $\mathrm{ICH}$ ), and Good Clinical Practice guidelines, and any other local and national guidelines from the Department of Health, Abu Dhabi, UAE. The study obtained research ethics approval from the Department of Health, Abu Dhabi, centralized research ethics committee.

Study Design: Following a cross-sectional design, data, including but not limited to, demographics, RTPCR test results, date of admission and discharge, disease severity, lab work, radiological examinations, and treatment, were retrospectively collected for the patients between March until June 2020, the highly active phase of the contagion [8].

Inclusion and Exclusion Criteria: Patient data were abstracted from the records provided the following inclusion criteria were met: a) patients were aged above 18 years of age, irrespective of their nationality, b) had a confirmed positive COVID-19 nuclei acid test detected using the real-time reverse transcriptasepolymerase chain reaction, $c$ ) both male and female, and d) cases presented to the emergency department, in-patient units of the two hospitals, and the local screening tents which were designated for COVID-19. Patients not meeting the above criteria, seen at the private hospitals and other regions, and with incomplete charts or missing data were excluded.

\section{Data Analysis}

Data were analysed using SPSS (IBM, Chicago) Version 26, and results presented using descriptive statistics. Interrater reliability to assess the data differences between the data abstractors was evaluated using Cohen's kappa coefficient [10]. Interrater reliability for the 24 data abstractors was 0.79 , indicating good agreement of the data collected between them. Selection and operator bias were excluded by involving multiple data abstracters and subjecting the data to Interrater reliability test. The Chi-square test was applied to assess the association between the outcome of the disease and other comorbidity conditions and sociodemographic variables. A p-value of $\leq 0.05$ was considered statistically significant. The variables, which showed statistically significant association, was included in the simple and multiple binary logistic regression to determine the crude and adjusted Odds Ratio (OR) [11]. The 95\% confidence interval for crude and adjusted Odds Ratio was calculated to find the statistically significant variables. All the variables indicating statistical significance using simple logistic regression were also analyzed for multiple logistic regression.

\section{Results}

A total of 3072 patients, meeting the inclusion and exclusion criteria and confirmed positive for Covid19 by the reverse-transcriptase polymerase chain reaction (RT-PCR) constituted the study population. More than half $(1630 / 3072,53 \%)$ of the patients were in the age group between $31-50$ years (Table 1$)$, followed by older patients above 51 years of age $(966 / 3072,31.5 \%)$. Less than one-fifth of the total Covid19 patients were females (659/3072, 21.5\%), the majority being male patients (table). Covid19 was 
widespread among the Asian population (2187/3072, 71.2\%), followed by Middle Eastern Arabs $(716 / 3072,23.3 \%)$. Patients with social habits, irrespective of the social habit were more likely for Covid19 infection (1712/3072, 85.8\%), compared to those without any social habit (Table 1 ).

Table 1

Demographics of Adult Covid19 Patients

Admitted to the Public Hospitals in Al Ain, the

Eastern Region of the United Arab Emirates

\begin{tabular}{|llll|}
\hline Characteristics & Category & $\mathbf{n}$ & $\%$ \\
\hline Age (Years) & $18-30$ & 476 & 15.5 \\
& $31-50$ & 1630 & 53.1 \\
& $51-65$ & 770 & 25.1 \\
\cline { 2 - 4 } Gender & $>66$ & 196 & 6.4 \\
\hline Nationality & Male & 2413 & 78.5 \\
& Female & 659 & 21.5 \\
& Asian & 2187 & 71.2 \\
& Middle East & 716 & 23.3 \\
\cline { 2 - 4 } Social Habit & Others & 167 & 5.4 \\
& Some Habit & 1712 & 85.8 \\
\cline { 2 - 4 } & No Habit & 283 & 14.2 \\
\hline
\end{tabular}

Diabetes Mellitus was the most predominant comorbidity observed among adult Covid19 patients, more than one quarter of the patients presented with Diabetes Mellitus (792/3072, 26.8\%) (Fig. 1).

Hypertension (759/3072, 25.7\%) was the second most common comorbidity among Covid 19 patients, followed by heart disease including patients with dyslipidemia (283/3072, 9.6\%). Respiratory (130/3072, 4.4\%) Kidney (112/3072, 3.8\%), Obesity (102/3072, 3.4\%), Immunocompromised (80/3072, 2.7\%), diseases were below five percent for Covid19 patients. Hematological and Liver diseases were not common, less than one percent of the patients (Fig. 1).

Subgroup analysis of the data indicated a statistically significant $(p<0.001)$ positive association between age and survival. Higher age enhanced mortality rate. The mortality rate was less than $0.5 \%$ for the Covid 19 patients in the age group of 18-30 Years. Between 31-50 years, the death rate was less than $2 \%$ and escalated to $5.7 \%$ and $13.5 \%$, for the older age group of $51-65$ years and $66+$ years, respectively (Table 2). Statistically significant association was not observed for the disease outcomes either for the gender differences and for patients with some social habits (Table 2). In contrast, despite the large number of Asian patients who contracted Covid19 infection (2080/3072,97.4\%), the mortality rate was low at $2.6 \%$, compared to statistically significant $(P<0.005)$ higher mortality in the Middle Eastern Arab $(4.6 \%)$ and other's (immigrants from the America's, Europe and Africa, $6.3 \%$, Table 2). 
Table 2

Association between Patient Characteristics and Survival of Adult Covid19 Patients Admitted to the Public Hospitals in Al Ain, the Eastern Region of the United Arab

Emirates

\begin{tabular}{|c|c|c|c|c|c|c|}
\hline \multirow[t]{3}{*}{ Characteristics } & \multirow[t]{3}{*}{ Category } & \multicolumn{4}{|c|}{ Outcome } & \multirow[t]{3}{*}{$\mathrm{P}$} \\
\hline & & \multicolumn{2}{|c|}{ Survival } & \multicolumn{2}{|c|}{ Deceased } & \\
\hline & & $\mathrm{n}$ & $\%$ & $\mathrm{n}$ & $\%$ & \\
\hline \multirow[t]{4}{*}{ Age (Years) } & $18-30$ & 462 & 99.6 & 2 & 0.4 & \multirow[t]{4}{*}{$<0.001$} \\
\hline & $31-50$ & 1566 & 98.4 & 25 & 1.6 & \\
\hline & $51-65$ & 706 & 94.3 & 43 & 5.7 & \\
\hline & $>66$ & 160 & 86.5 & 25 & 13.5 & \\
\hline \multirow[t]{2}{*}{ Gender } & Male & 2273 & 96.7 & 77 & 3.3 & \multirow[t]{2}{*}{ Not Significant } \\
\hline & Female & 621 & 97.2 & 18 & 2.8 & \\
\hline \multirow[t]{3}{*}{ Nationality } & Asian & 2080 & 97.4 & 55 & 2.6 & \multirow[t]{3}{*}{$<0.005$} \\
\hline & Middle East Arab & 665 & 95.7 & 30 & 4.3 & \\
\hline & Others & 149 & 93.7 & 10 & 6.3 & \\
\hline \multirow[t]{2}{*}{ Social Habit } & Some Habit & 1638 & 97.4 & 44 & 2.6 & \multirow[t]{2}{*}{ Not Significant } \\
\hline & No Habit & 249 & 97.6 & 6 & 2.4 & \\
\hline
\end{tabular}

Further, subgroup analysis of the association between the patient comorbidities and disease outcome yielded interesting results. Kidney disease as a comorbidity for adult Covid19 patients was found to be detrimental for survival. The mortality rate was almost eight-fold high (19.4\%) and statistically significant $(p<0.001)$, as compared to other Covid19 infected patients without kidney disease $(2.4 \%)$ (Table 3$)$.

Comorbidities such as heart disease $(p<0.01)$, hypertension $(p<0.001)$, and diabetes mellitus $(p<0.001)$, escalated mortality significantly by $2-3$ fold, as compared to the patients without these comorbidities (Table 3). Other associated comorbidities such as respiratory, hematological, liver diseases, and immunocompromising disease and obesity did not significantly impact Covid19 adult patients survived when compared with other Covid19 patients without these comorbidities (Table 3). 
Table 3

Assessment of Association between Patient Comorbidities and Survival for Adult Covid19 Patients Admitted to the Public Hospitals in Al Ain, the Eastern Region of the United Arab Emirates

\begin{tabular}{|c|c|c|c|c|c|c|}
\hline \multirow[t]{3}{*}{ Comorbidity } & \multirow[t]{3}{*}{ Category } & \multicolumn{4}{|c|}{ Outcome } & \multirow[t]{3}{*}{ P Value } \\
\hline & & \multicolumn{2}{|c|}{ Survived } & \multicolumn{2}{|c|}{ Deceased } & \\
\hline & & $\mathrm{n}$ & $\%$ & $\mathbf{n}$ & $\%$ & \\
\hline \multirow[t]{2}{*}{ Kidney disease } & No & 2716 & 97.6 & 68 & 2.4 & \multirow[t]{2}{*}{$<0.001$} \\
\hline & Yes & 83 & 80.6 & 20 & 19.4 & \\
\hline \multirow[t]{2}{*}{ Heart disease/Dyslipidemia } & No & 2546 & 97.2 & 73 & 2.8 & \multirow[t]{2}{*}{$<0.01$} \\
\hline & Yes & 253 & 94.4 & 15 & 5.6 & \\
\hline \multirow[t]{2}{*}{ Diabetes Mellitus } & No & 2069 & 97.9 & 45 & 2.1 & \multirow[t]{2}{*}{$<0.001$} \\
\hline & Yes & 730 & 94.4 & 43 & 5.6 & \\
\hline \multirow[t]{2}{*}{ Hypertension } & No & 2100 & 97.6 & 52 & 2.4 & \multirow[t]{2}{*}{$<0.001$} \\
\hline & Yes & 699 & 95.1 & 36 & 4.9 & \\
\hline \multirow[t]{2}{*}{ Respiratory disease } & No & 2681 & 97.1 & 81 & 2.9 & \multirow[t]{2}{*}{ Not Significant } \\
\hline & Yes & 118 & 94.4 & 7 & 5.6 & \\
\hline \multirow[t]{2}{*}{ Hematology } & No & 2781 & 97 & 87 & 3 & \multirow[t]{2}{*}{ Not Significant } \\
\hline & Yes & 18 & 94.7 & 1 & 5.3 & \\
\hline \multirow[t]{2}{*}{ Immunocompromised } & No & 2727 & 97 & 83 & 3 & \multirow[t]{2}{*}{ Not Significant } \\
\hline & Yes & 72 & 93.5 & 5 & 6.5 & \\
\hline \multirow[t]{2}{*}{ Liver Disease } & No & 2792 & 97 & 87 & 3 & \multirow[t]{2}{*}{ Not Significant } \\
\hline & Yes & 7 & 87.5 & 1 & 12.5 & \\
\hline \multirow[t]{2}{*}{ Obesity } & No & 2706 & 97 & 83 & 3 & \multirow[t]{2}{*}{ Not Significant } \\
\hline & Yes & 93 & 94.9 & 5 & 5.1 & \\
\hline
\end{tabular}

In order to predict the association between critical patient characteristics and comorbidity, against mortality, the Odds Ratio was estimated. Patient age and nationality were chosen for patient characteristics and, the comorbidities identified included heart disease/dyslipidemia, hypertension, kidney disease, and patients with diabetes mellitus. Higher age of Covid19 patients between 51 and 65 years, significantly decreased the odds for survival (Crude OR 14.1, Confidence Interval 3.4-58.4, p < 0.001) and (Adjusted OR 12.3, Confidence Interval 2.9-52.4, p <0.001), and patient age beyond 66 years, further significantly decreased the odds for survival (Crude OR 36.1, Confidence Interval 8.5-154.1, P,0.001) and (Adjusted OR 26.6, Confidence Interval 5.7-123.8, p < 0.001) (Table 4). Kidney disease as comorbidity 
significantly diminished the survival rates for Covid19 patients (Crude OR 9.6, Confidence Interval 5.616.6, $p<0.001$ ) and (Adjusted OR 5.7, Confidence Interval 3.0-10.8, $p<0.001$, Table 4), as compared to those without kidney dysfunction. Patient nationality and other comorbidity related risk factors such as heart disease, hypertension, and diabetes did not significantly alter the odds (adjusted OR) for the survival of Covid19 patients in our study. Additionally, the majority of patients were not treated with antibiotics $(70 \%, 2154 / 3072)$, those severely ill received Augmentin, Tazocin, Amoxicillin and Doxycycline. Less than $10 \%(7.2 \%, 224 / 3072)$ of the patients did not receive any antiviral therapy, others received hydroxyquinoline and Favipiravir as monotherapy, or in combination (data not shown). 
Table 4

Odds ratio (crude and adjusted) for predicting the association between critical patient characteristics and comorbidities against mortality for Covid19 infection

\begin{tabular}{|c|c|c|c|c|c|c|c|}
\hline \multirow[t]{2}{*}{ Characteristics } & \multirow[t]{2}{*}{ Group } & \multicolumn{3}{|c|}{ Crude } & \multicolumn{3}{|c|}{ Adjusted } \\
\hline & & OR & $\mathrm{Cl}$ & $\mathbf{P}$ & OR & $\mathrm{Cl}$ & $\mathbf{P}$ \\
\hline \multirow[t]{4}{*}{ Age (Years) } & $18-30$ & 1 & - & - & 1 & - & - \\
\hline & $31-50$ & 3.7 & $\begin{array}{l}0.9- \\
15.6\end{array}$ & $\begin{array}{l}\text { Not } \\
\text { Significant }\end{array}$ & 3.3 & $\begin{array}{l}0.8- \\
14.2\end{array}$ & $\begin{array}{l}\text { Not } \\
\text { Significant }\end{array}$ \\
\hline & $51-65$ & 14.1 & $\begin{array}{l}3.4- \\
58.4\end{array}$ & $<0.001$ & 12.3 & $\begin{array}{l}2.9- \\
52.4\end{array}$ & $<0.001$ \\
\hline & $>65$ & 36.1 & $\begin{array}{l}8.5- \\
154.1\end{array}$ & $<0.001$ & 26.6 & $\begin{array}{l}5.7- \\
123.8\end{array}$ & $<0.001$ \\
\hline \multirow[t]{3}{*}{ Nationality } & Asia & 1 & - & - & 1 & - & - \\
\hline & $\begin{array}{l}\text { Middle East } \\
\text { Arab }\end{array}$ & 1.7 & $\begin{array}{l}1.1- \\
2.7\end{array}$ & $<0.05$ & 0.9 & $\begin{array}{l}0.5- \\
1.5\end{array}$ & $\begin{array}{l}\text { Not } \\
\text { Significant }\end{array}$ \\
\hline & Others & 2.5 & $\begin{array}{l}1.3- \\
5.1\end{array}$ & $<0.01$ & 2.1 & $\begin{array}{l}1.0- \\
4.5\end{array}$ & $\begin{array}{l}\text { Not } \\
\text { Significant }\end{array}$ \\
\hline \multirow{2}{*}{$\begin{array}{l}\text { Heart } \\
\text { disease/Dyslipidemia }\end{array}$} & No & 1 & - & - & 1 & - & - \\
\hline & Yes & 2.1 & $\begin{array}{l}1.2- \\
3.7\end{array}$ & $<0.05$ & 0.6 & $\begin{array}{l}0.3- \\
1.3\end{array}$ & $\begin{array}{l}\text { Not } \\
\text { Significant }\end{array}$ \\
\hline \multirow[t]{2}{*}{ Hypertension } & No & 1 & - & - & 1 & - & - \\
\hline & Yes & 2.1 & $\begin{array}{l}1.4- \\
3.2\end{array}$ & $<0.001$ & 0.8 & $\begin{array}{l}0.5- \\
1.3\end{array}$ & $\begin{array}{l}\text { Not } \\
\text { Significant }\end{array}$ \\
\hline \multirow[t]{2}{*}{ Kidney disease } & No & 1 & - & - & 1 & - & - \\
\hline & Yes & 9.6 & $\begin{array}{l}5.6- \\
16.6\end{array}$ & $<0.001$ & 5.7 & $\begin{array}{l}3.0- \\
10.8\end{array}$ & $<0.001$ \\
\hline \multirow[t]{2}{*}{ Diabetes Mellitus } & No & 1 & - & - & 1 & - & - \\
\hline & Yes & 2.7 & $\begin{array}{l}1.8- \\
4.1\end{array}$ & $<0.001$ & 1.3 & $\begin{array}{l}0.8- \\
2.1\end{array}$ & $\begin{array}{l}\text { Not } \\
\text { Significant }\end{array}$ \\
\hline
\end{tabular}

\section{Discussion}

The UAE was exposed to other coronavirus epidemics, such as the Severe Acute Respiratory Syndrome (SARS) outbreak in 2002 and the spread of Middle East Respiratory Syndrome (MERS) in 2012 [12-13]. In spite, limited information about patient characteristics and clinical management of the epidemics are available $[5,12]$. The UAE is the second worst affected country, among the GCC countries, by the Covid19 disease, preceded by Saudi Arabia with a total of 361,000 positive cases and approximately 6000 deaths 
[14]. Men were disproportionately affected by Covid 19 as compared to women, less that one quarter of the Covid19 patients were women in our study [15]. Higher neutralizing antibodies, smaller lung size, lower chance of immune dysregulation and the differential expression of the angiotensin-converting enzyme 2-the viral receptor, are postulated to contribute to the gender difference in Covid19 infectivity [16]. A large proportion of the UAE population are Asian, especially the South East Asian's from Pakistan, India, Bangladesh, Sri Lanka, Philippines and Nepal [17]. A vast majority of the South East Asian workforce are laborers who often live-in crowded housing conditions, and are at a higher risk for contracting communicable diseases [17] thus explaining the higher Covid19 infectivity amongst the Asian population (Table 1). Lower social status is also reported to be a risk factor for Covid19 infection [18-19]. A national cohort study of over 7000 subjects has shown that diabetes, impaired fasting glucose, hypercholesterolemia, and hypertension are highly prevalent in young adulthood in the UAE [20]. Comorbidities such as diabetes and hypertension were observed in more than one quarter of our Covid19 patients, supporting earlier observations reported by Guan [21] and Xu [22], that patients with diabetes and hypertension were at a higher risk for severe Covid19. Despite the fact that the Asian population was the most Covid19 infected, their mortality rate $(2.6 \%$, Table 2$)$ was the lowest compared to the Middle East Arabs (4.3\%, Table 2) and other combined nationalities from the Americas, Europe and Africa (6.3\%, Table 2). Similar mortality rates from Covid19 disease between the Asian population and the Caucasian white population was observed in the United States [23]. The observed mortality rates were almost 1.7 times lower than that for the Black and Hispanic population [23].

Despite the myriad of comorbidities for Covid19 patients observed in our study, kidney disease, heart disease, diabetes and hypertension, significantly contributed to the mortality rates (Table 3). Almost, twofold increase in mortality rate was observed for Covid19 patients with heart disease, diabetes and hypertension, when compared with the patients without these comorbidities (Table 3). An eight-fold increase $(19.4 \%, p<0.001)$ in mortality rate was observed in Covid19 patients with kidney disease, as compared to those without kidney disease (2.4\%). Odds Ratio estimation further validated that kidney disease as a comorbidity significantly diminished the survival rates for Covid19 patients (Crude OR 9.6, Confidence Interval 5.6-16.6, p<0.001) and (Adjusted OR 5.7, Confidence Interval 3.0-10.8, p<0.001, Table 4), as compared to those without kidney dysfunction. Gansevoort \& Hilbrands, recently demonstrated that Covid19 patients with kidney dysfunction had higher rates of mortality, when compared to the patients with heart disease, diabetes and hypertension comorbidities [24]. Advanced ages of Covid19 patients between 51 and 65 years, significantly decreased the odds for survival (Adjusted OR 12.3, Confidence Interval 2.9-52.4, $\mathrm{p}<0.001$ ), and patient age beyond 66 years significantly enhanced mortality (Adjusted OR 26.6, Confidence Interval 5.7-123.8, $p<0.001$ ) (Table 4). Advancing age may also be associated with various comorbidities and therefore older patient age has been noted as an independent risk factor for Covid19 mortality [25].

Interestingly, despite the lower social status of the immigrant labourers and, the multicultural and multiethnic patient population in our study, the observations are in accordance with the previously published reports from other Covid19 disease affected countries [21, 23,25]. The strengths of the study is the facts that this is the first report describing patient characteristics and outcomes for Covid19 patients from the 
UAE, and the data was collected from Covid19 patients hospitalized at the only two public hospitals in Al Ain, that catered to more than $98 \%$ of the total positive Covid 19 case load. Our study has several limitations: a) the data for the study was retrospectively collected from pre-recorded patent medical records making it difficult to assess any temporal relationships between the variables; $b$ ) the retrospective design of the study enables assessment of association and not causation; $c$ ) other confounding factors may have been overlooked, and d) although $85.8 \%$ of the Covid19 patients had some social habit (Table 1), the risk did not affect their survival (2.6 Vs 2.4, Social Habit Vs No Social Habit, Table 2), the reasons for which need to be investigated. Data abstraction by multiple abstractors blinded to the study hypothesis and assessment of interrater reliability for the data collected helped to prevent selection bias.

In summary, our study highlights that although Asian population was the highest infected by Covd19, their mortality rate was low (2.6\%), compared to other nationalities. Older ages above 51 years decreased the odds of survival significantly. Despite other comorbidity risks, kidney dysfunction contributed to enhanced mortality by over eight-fold and reduced the odds of survival (Adjusted OR 26.6), compared to those patients without kidney dysfunction. Our findings are important in the management of the Covid19 disease in the region with similar economic, social, cultural and ethnic background.

\section{Declarations}

\section{Funding}

This study was not supported by funds or grants. No funding sources to declare.

\section{Availability of data and materials}

The datasets generated and/or analyzed during the current study ae not publicly available due to the institutions policy to code and archive data in a central repository of the hospital, but are available from the corresponding author on reasonable request.

\section{Competing interests}

The authors declare that they have no competing interests.

\section{Consent for publication}

Obtaining written informed consents were exempted by the central human research ethics committee at the department of health Abu Dhabi, for retrospective review of patient charts. No personal identifying information was collected for the patients, both subject privacy and patient data confidentiality was strictly adhered to in accordance with the international and national guidelines.

\section{ICH-GCP Guidelines and Research Ethics approval:}

The methods of the study were carried out in accordance with the International Conference for Harmonization $(\mathrm{ICH})$, and Good Clinical Practice guidelines, and any other local and national guidelines 
from the Department of Health, Abu Dhabi, UAE. The study obtained research ethics approval from the Department of Health, Abu Dhabi, centralized research ethics committee.

\section{Acknowledgements}

The authors are thankful to the management of Tawam Hospital and the Al Ain hospital for providing the time to conduct the study.

\section{Author Contribution Statement}

Concept and design (SCN, HIG). Feasibility Assessment (AAK, INK, AAS), Patient Care (HIG, AAK, AAS) Literature Search \& Updates (AAS, SCN, AAK, INK), Data Acquisition \& Organization (INK, HIA, AAS, AHA, ARS, ARA, AIS, MMF, ARA, AMH, KMB, HBC, MNA, SSA, MAA, FAS, RSS, FWH, AWA, WFD), Data Analysis (JS, AAK, HIG, INK, SCN), Data Interpretation (SCN, HIG, AAK), Manuscript Preparation (SCN, AAK, HIG), Manuscript Review \& Approval (all authors).

\section{References}

1. Zhu H., Wei L, Niu, P. The novel coronavirus outbreak in Wuhan, China. Global health research and policy 2020, 5, 135-136.

2. Cucinotta D, Vanelli M. WHO Declares COVID-19 a Pandemic. Acta Biomed. 2020, Mar 19;91(1):157160.

3. Singhal T. A Review of Coronavirus Disease (COVID-19). Indian journal of pediatrics, 2020, 87(4), 281-286.

4. https://www.worldometers.info/coronavirus/? fbclid=IwAR2RSsOMsu6XxMiOJ1WHNcSfC2TCYYrj4a0bUMdJW3VUXwSrj3WSNSCxY0Q Accessed on December 20, 2020

5. Nair SC, Ibrahim H, Celentano DD. Clinical trials in the Middle East and North Africa (MENA) Region: grandstanding or grandeur? Contemp Clin Trials. 2013, 36:704-10.

6. Ibrahim H, Kamour AM, Harhara T, Gaba WH, Nair SC. Covid-19 pandemic research opportunity: Is the Middle East \& North Africa (MENA) missing out? Contemp Clin Trials. 2020, 96:106-110.

7. https://www.arabianbusiness.com/politics-economics/407542-revealed-the-importance-of-china-touae-businesses Accessed December 20, 2020

8. Zattar MT Charting the UAE's battle against Covid19 (commentary) published online $7^{\text {th }}$ August 2020, doi:10.1038/nmiddleeast.2020.84 https://www.natureasia.com/en/nmiddleeast/article/10.1038/nmiddleeast.2020.84 Accessed December 22020

9. Organization of Economic Cooperation \& Development, October 19 2020, http://www.oecd.org/coronavirus/policy-responses/what-is-the-impact-of-the-covid-19-pandemic-onimmigrants-and-their-children-e7cbb7de/ Accessed December 18, 2020 
10. McHugh M. L. (2012). Interrater reliability: the kappa statistic. Biochemia medica, 22(3), 276-282.

11. Szumilas M. (2010). Explaining odds ratios. Journal of the Canadian Academy of Child and Adolescent Psychiatry 19(3), 227-229.

12. Alkendi F, Nair SC, Hashmey R. Descriptive Epidemiology, Clinical Characteristics and Outcomes for Middle East Respiratory Syndrome Coronavirus (MERS-CoV) Infected Patients in AlAin - Abu Dhabi Emirate. J Infect Public Health 2019, 12 (1) 37-42.

13. Hui DS, Memish ZA, Zumla A. Severe acute respiratory syndrome vs. the Middle East respiratory syndrome. Curr Opin Pulm Med. 2014 May;20(3):233

14. https://www.reuters.com/article/uk-health-coronavirus-gulf/gcc-countries-surpass-1-million-covid-19cases-reuters-tally-idUKKBN283153 Accessed December 102020

15. Sharma, G., Volgman, A. S., \& Michos, E. D. Sex Differences in Mortality From CoVID-19 Pandemic: Are Men Vulnerable and Women Protected?. JACC. Case reports, 2020, 2(9), 1407-1410.

16. Falahi, S., \& Kenarkoohi, A. (2020). Sex and gender differences in the outcome of patients with COVID-19. Journal of medical virology, 10.1002/jmv.26243. Advance online publication. https://doi.org/10.1002/jmv.26243

17. Sulaiman, N., Elbadawi, S., Hussein, A., et al. Prevalence of overweight and obesity in United Arab Emirates Expatriates: the UAE National Diabetes and Lifestyle Study. Diabetology \& metabolic syndrome 2017,9 , 88-91.

18. Patel JA, Nielsen FBH, Badiani AA, et al.. Poverty, inequality and COVID-19: the forgotten vulnerable. Public Health. 2020 Jun;183:110-111.

19. Segerstrom SC, Miller GE. Psychological stress and the human immune system: a meta-analytic study of 30 years of inquiry. Psychol Bull. 2004 Jul;130(4):601-30.

20. Alzaabi A., Al-Kaabi J., Al-Maskari F., Farhood, AF., Ahmed, L. A.Prevalence of diabetes and cardiometabolic risk factors in young men in the United Arab Emirates: A cross-sectional national survey. Endocrinology, diabetes \& metabolism, 2019, 2(4), e00081

21. Guan WJ, Ni ZY, Hu Y, et al; China Medical Treatment Expert Group for Covid-19. Clinical Characteristics of Coronavirus Disease 2019 in China. N Engl J Med. 2020 Apr 30;382(18):17081720.

22. Xu Z, Shi L, Wang Y, et al. Pathological findings of COVID-19 associated with acute respiratory distress syndrome. Lancet Respir Med. 2020 Apr;8(4):420-422. Erratum in: Lancet Respir Med. 2020 Feb 25

23. https://www.apmresearchlab.org/covid/deaths-by-race Accessed December 22020

24. Gansevoort RT, Hilbrands LB. CKD is a key risk factor for COVID-19 mortality. Nat Rev Nephrol. 2020 Dec;16(12):705-706.

25. Ho FK, Petermann-Rocha F, Gray SR, et al. (2020) Is older age associated with COVID-19 mortality in the absence of other risk factors? General population cohort study of 470,034 participants. PLoS ONE 15(11): e0241824. 
Figures

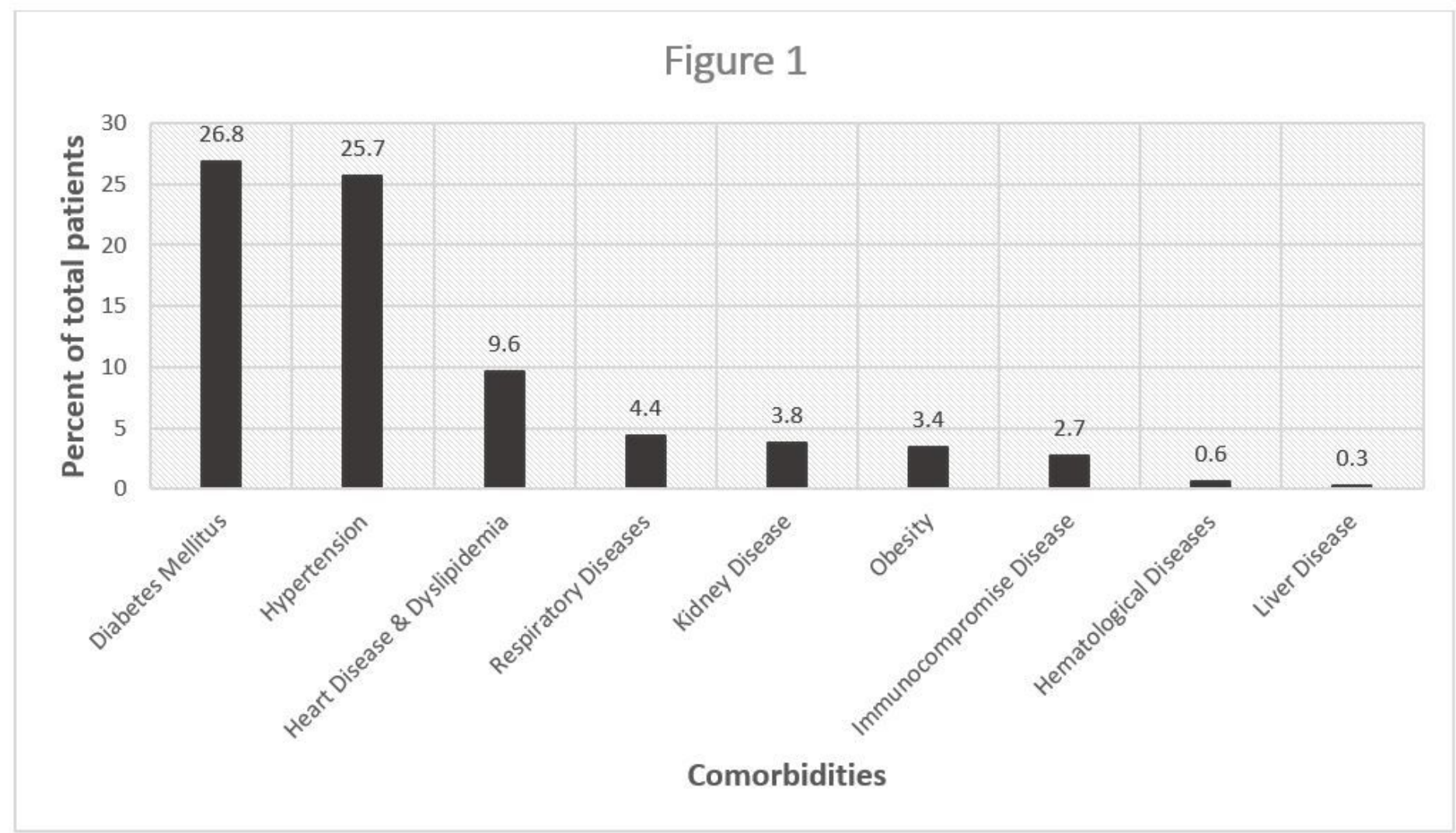

Figure 1

Percentage of total patients infected with Covid19 presenting with various comorbidities 